\title{
Effect of Disinfectants on Elastic Modulus, Flexural Strength and Color Stability of Denture Base Resins
}

\section{Tobias Bensel1, Jens J. Bock², Lisa Zumpe¹, Sonia Mansour ${ }^{3}$, Nadine Blümel1, Julia Seeliger4, Arne F. Boeckler ${ }^{1}$}

\author{
${ }^{1}$ Department of Prosthodontics, University of Halle, Halle, Germany \\ ${ }^{2}$ Private Orthodontic Practice, Fulda, Germany \\ ${ }^{3}$ Department of Prosthodontics, Gerodontology and Craniomandibular Disorders, Charité-University Medicine Berlin, \\ Berlin, Germany \\ ${ }^{4}$ Department of Orthodontics, Technical University Dresden, Dresden, Germany \\ Email: info@zahnarzt-am-rain.de
}

How to cite this paper: Bensel, T., Bock, J.J., Zumpe, L., Mansour, S., Blümel, N., Seeliger, J. and Boeckler, A.F. (2018) Effect of Disinfectants on Elastic Modulus, Flexural Strength and Color Stability of Denture Base Resins. Open Journal of Stomatology, 8, 135-148.

https://doi.org/10.4236/ojst.2018.84013

Received: March 22, 2018

Accepted: April 24, 2018

Published: April 27, 2018

Copyright $\odot 2018$ by authors and Scientific Research Publishing Inc. This work is licensed under the Creative Commons Attribution International License (CC BY 4.0).

http://creativecommons.org/licenses/by/4.0/

\begin{abstract}
Objective: Infection control protocols dictate the disinfection of dentures. There are no products available which are designed for the specific use of disinfecting dentures. The objective of this study was to investigate the impact of chemical disinfectants on elastic modulus, flexural strength and color stability of denture base resins. Methods: 256 specimens from four acrylic denture base resins were manufactured. Two cold-curing denture base resins: PalaXpress (Heraeus Kulzer, Hanau, Germany), Futura Gen (Schuetz Dental, Roßbach, Germany) and two heat-curing denture base resins: Paladon 65 (Heraeus Kulzer, Hanau, Germany), FuturAcryl 2000 (Schuetz Dental, Roßbach, Germany) were used. Three chemical disinfecting agents were tested: Impresept, D050 Instru-Gen, Stammopur DR. Specimens were stored in distilled water and in chemical disinfecting agents. They were divided randomly into groups. E-Modulus and flexural strength were measured using the three-point bending test. Color changes $(\Delta \mathrm{E})$ were determined spectrophotometrically. Results: The disinfection agents showed no significant influence on the E-modulus compared to distilled water (Acrylic vs. distilled water from (Futura Gen) $2688.80 \pm 230.78$ vs. $2766.60 \pm 91.22 \mathrm{MPa}$ to (PalaXpress) $3004.20 \pm 26.40$ vs. $2851.00 \pm 95.23 \mathrm{MPa}$ ). Flexural strength after storage in distilled water and disinfection did not differ significantly (Acrylic vs. distilled water from (Paladon65) $27.28 \pm 1.30$ vs. $28.42 \pm 0.84 \mathrm{~N} / \mathrm{mm}^{2}$, ( $\left.\mathrm{p}>0.05\right)$ to (PalaXpress) $30.88 \pm 0.25$ vs. $29.68 \pm 0.79 \mathrm{~N} / \mathrm{mm}^{2}, \mathrm{p}<0.001$ ). Disinfection caused a significant color change with Impresept of Paladon 65 ( $\mathrm{p} \leq 0.001)$, FuturaAcryl 2000 with Stammopur DR and D 050 Instru-Gen $(\mathrm{p} \leq 0.001)$.
\end{abstract}


Conclusions: The investigated disinfection agents did not influence elastic modulus and flexural strength of denture base resins negatively. $\Delta \mathrm{E}$-values were in a range of 1 to 2 . Thus, the detected color changes may be marginal. Clinical relevance: Single use disinfections are feasible for acrylic dentures regarding to elastic modulus and flexural strength.

\section{Keywords}

Cross Infection, Chemical Disinfectants, Denture Base Resins, Material Characteristics, Disinfection

\section{Introduction}

Opportunistic and pathogenic microorganisms use the oral cavity as a reservoir [1]. While routine dental practice, there could be a high risk of contamination and infection that may even cause systemic infections [2]. Pathogens transfer from patients to members of the dental team and vice versa. Transfer of pathogens may also take place from patient to patient without intervention of the dental team via the transmission routes of contaminated surfaces, instruments or dentures. In general, the major vectors of cross-contamination of pathogens are the patient's saliva and blood [2] [3] [4].

As a result of the demographic change in the industrialized countries, prosthodontic treatment will increase [5]. With advancing age, the general health of patients will decline and thus older patients usually become more prone to infections. Overall, there might be a high risk of infection for all participants of dental treatment, including patients, providers, dental assistants and laboratory technicians. The omission of a proper disinfection of dental prostheses might increase the risk for transmission of communicable diseases (e.g. Hepatitis B virus) and facultative pathogenic microorganisms (e.g. Pseudomonas aeruginosa). A higher rate of Hepatitis-B-infestation compared to the average population is shown on dental technicians [6] [7]. Therefore, there is a need to reduce the possible transmission routes of pathogens in the dental setting.

The disinfection of dentures before and after contact with patients is theoretically an obligation [8] [9]. Dentures contact mucous membranes and should be cleaned of all microorganisms before handling them. These items require high-level disinfection using chemical disinfectants like aldehydes. The inactivation of pathogens without affecting the material structure of dentures is the intention of the chemical disinfecting process [9]. The definition of a high-level disinfectant is a sterilant that is used for a short contact time (e.g., 20 minutes for $2 \%$ glutaraldehyde), reaching a $6-\log _{10}$ kill of an appropriate Mycobacterium species. The aim of the disinfection process of dental restorations should be the elimination of pathogens to prevent transmission of infection [7] [10] [11].

There are no agents produced exclusively for disinfection of acrylic dentures. Thus, disinfecting agents originally produced for disinfection of dental impres- 
sions are used generally. Aldehydes are the utilized agents for disinfecting acrylic dentures, which are mostly used. However, the material safety data sheets give no direct information regarding disinfection of acrylic dentures [12].

Therefore, the purpose of this in vitro study was to determine the effect of disinfection agents on the elastic modulus, flexural strength and color stability of different denture base resins. Four different Polymethyl methacrylate-based (PMMA)-based resins and three disinfecting agents were used during this investigation.

The alternative hypothesis of this study is that the investigated chemical disinfecting agents have a significant influence on the elastic modulus, flexural strength and color change of different denture base materials.

\section{Material and Methods}

\subsection{Test Specimen}

256 test specimens consisting of four different denture acrylics were manufactured. Four PMMA-based resins were used: PalaXpress (Heraeus Kulzer, Hanau, Germany), Paladon 65 (Heraeus Kulzer, Hanau, Germany), Futura Gen (Schuetz Dental, Roßbach, Germany) and FuturAcryl 2000 (Schuetz Dental, Roßbach, Germany). PalaXpress and Futura Gen were cold-curing PMMA-based resins. Paladon 65 and FuturAcryl 2000 were heat-curing PMMA-based resins. Test specimens were designed prismatically according to DIN-EU-ISO-norm (3167) and were constructed with dimensions of $80 \times 10 \times 4 \mathrm{~mm}$. All test specimen surfaces were ground and polished, using granulation sizes of 220, 320, 800, 1200 and 2400 (RotoPol-35, Struers GmbH, Willich, Germany) (Figure 1).

For appearing the maximum water sorption and ensuring standardized water saturation, all specimens were inserted at $22^{\circ} \mathrm{C}$ in distilled water for 24 hours. For performing the three-point bending test under standardized conditions, the water saturated test specimens were subsequently incubated at $22^{\circ} \mathrm{C}$ (WTC Binder, Tuttlingen, Germany) aerobically for 24 hours.

Afterwards, the 256 test specimens were distributed into test groups. 220 test

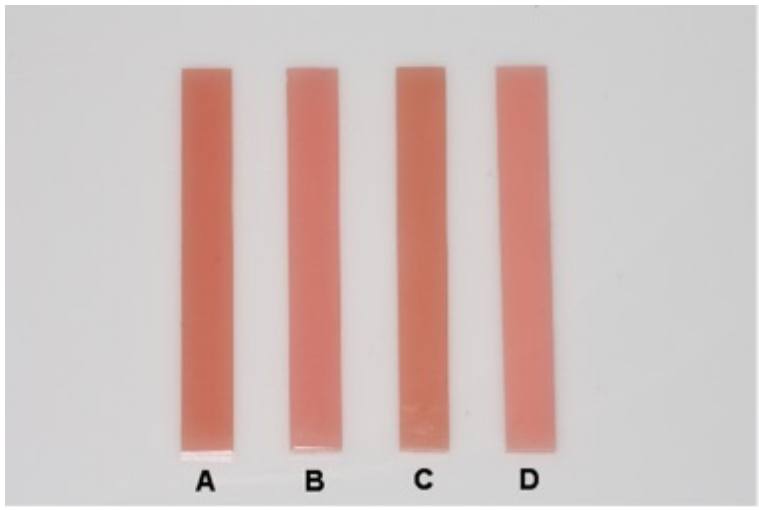

Figure 1. PMMA-based resins after polymerization: (A) PalaXpress; (B) Paladon 65; (C) Futura Gen; (D) FuturAcryl 2000. 
specimens were used for the three-point bending test. The color stability measurements were performed using 36 test specimens.

Finally, the influence of the disinfecting agents, consisting of Impresept (3M Espe, 3M Company, St. Paul, Minnesota, U.S.A.), Stammopur DR (Dr H Stamm, Berlin, Germany) and D 050 Instru-Gen (ad-Arztbedarf GmbH, Frechen, Germany), on the mechanical properties of the test specimens were investigated. Oxaldehyde and 1,5-Pentanedial were mentioned as active components of Impresept and were enclosed to the chemical group of aldehydes. The active components of Stammopur were listed as didecyl-dimethylammonium chloride (quaternary ammonium cation) and 1,5-Pentanedial. D 050 Instru-Gen were used with the active substances of sodium perborate and sodium benzoate with the chemical effect of oxidizing connections.

For conditioning of the test specimens, the disinfecting agents were prepared respective to the concentrations and exposure times regarding to the manufacturer instructions. Impresept was used with a concentration of $100 \%$ and disinfected the test specimen for ten minutes. The Stammopur disinfecting solution was prepared in a concentration of 3\% and was used with an exposure time of $60 \mathrm{mi}-$ nutes. The D 050 Instru-Gen disinfecting solution was prepared in a concentration of $2 \%$ and disinfected the test specimens of the test groups for 60 minutes.

Dry storage on the one hand and distilled water on the other hand were used in addition to the disinfecting agents as control groups. Test specimens, which were used in the distilled water group were stored for 60 minutes in distilled water. After expiration of the storage period (control group) and disinfecting period (including the test specimens of the distilled water group), the test specimens were rinsed with distilled water for one minute and dried manually. Then, the influence on the E-Modulus, flexural strength and color change were investigated.

\subsection{E-Modulus and Flexural Strength}

The E-Modulus and the flexural strength were measured using the three-point bending test as per DIN EN ISO 178.

A total of 220 test specimens were used and distributed into test groups. The first test group was stored dry. In the second test group distilled water was used as storage liquid. These two test groups were applied as control groups. In the third test group the influence of Impresept on the test specimens was investigated. The fourth test group was utilized to perform the impact of Stammopur on the test specimens. In the fifth test group D 050 Instru-Gen was used as disinfecting agent. Afterwards the preparation of each PMMA-based test specimen, three-point bending tests were performed using Zwick machine (ZWICKI TMZW, Zwick GmbH \& Co. KG, Ulm, Germany) (Figure 2).

The Zwick universal testing machine was constructed to perform numerous tests on materials and structures. The investigated test specimens were placed in the universal testing machine between the clamps and the inspection stamp. Each of the tested specimens was mounted on two $5 \mathrm{~mm}$ diameter support posts 


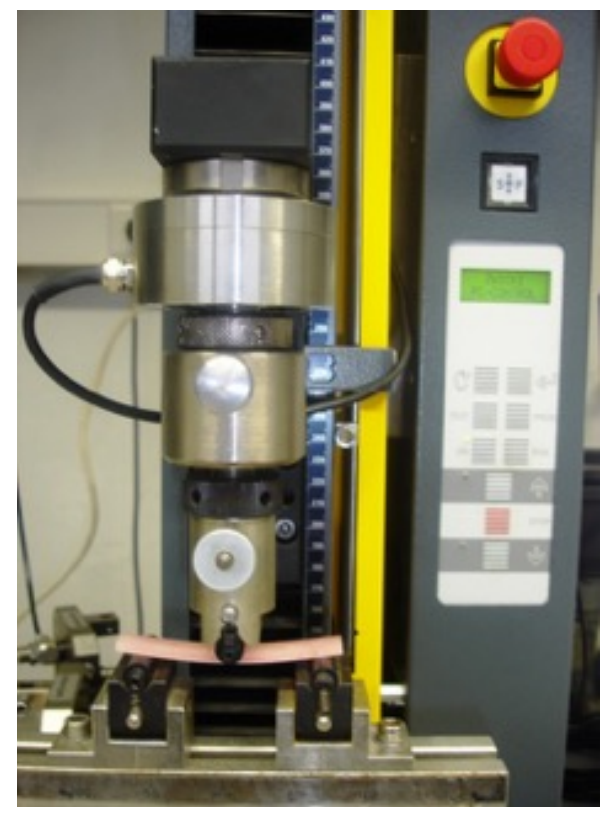

Figure 2. Three-point bending device on the Zwick universal testing machine (ZWICKI TMZW, Zwick GmbH \& Co. KG, Ulm, Germany).

$64 \mathrm{~mm}$ apart from each other. This distance was selected to be 16 times the specimens' thickness of $4 \mathrm{~mm}$. A plunger was used to apply a vertical force up to a maximum of $2 \mathrm{kN}$ to the center of the test specimen. The E-Modulus and flexural strength were determined at a cross-head speed of $2 \mathrm{~mm} / \mathrm{min}$. The radii of the abutments and plunger were $5 \mathrm{~mm}$. For determination of the E-Modulus and flexural strength, the test speed was kept at a consistent $2 \mathrm{~mm} / \mathrm{min}$. Analysis of the resulting data was performed using the test and calibration software testXpert II (Zwick GmbH \& Co. KG, Ulm, Germany).

\subsection{Color Stability}

36 test specimens were used and divided into test groups to determine the color change of the acrylic denture resins. Distilled water was used as storage liquid in the first test group. The first test group was applied as control group. The influence of Impresept on the test specimens was investigated in the second test group. Stammopur was used in the third test group. The fourth test group was prepared with D 050 Instru-Gen as disinfecting agent.

Afterwards the preparation of each test specimen, color change of the PMMA-based resins was quantified spectrophotometrically (Spectrophotometer VITA Easyshade, VITA Zahnfabrik, Bad Säckingen, Germany). The spectrophotometer was calibrated prior to collecting color data from the specimens. Measurements were performed at ten different positions of each test specimen before and after storing in the test liquid for the defined reaction time of the investigated disinfection agents. For standardized positioning of the spectrophotometer, a $1.5 \mathrm{~mm}$ thick transparent suck-down template was fabricated (Erko- 
dur, Erkodent $\mathrm{GmbH}$, Pfalzgrafenweiler, Germany). A white paper board was used as the background for the specimens during the measurement process to guarantee standardized conditions.

\subsection{Statistics}

Means were calculated and data were evaluated statistically. Statistical analyses were performed using SPSS 17.0 for Windows (SPSS Inc., Chicago, IL, U.S.A.). Normal distribution of the data was attested (Kolmogorov-Smirnov-test) and significant differences between the groups were detected using the Student's $\mathrm{t}$-test and the single factor variance analysis (ANOVA) were used. The level of significance was set to $5 \%(\mathrm{p} \leq 0.05)$. Significant results were analyzed using the post-hoc test (Bonferroni).

\section{Results}

\subsection{E-Modulus}

Results are given as means \pm standard deviation (Figure 3, Table 1). E-modulus data of test specimens which were stored dry ranged from $2867.80 \pm 122.38 \mathrm{MPa}$ (minimum) to $3149.20 \pm 77.61 \mathrm{MPa}$ (maximum). The storage of the PalaXpress test specimens in distilled water led to significant reduction of the E-modulus $(2851.00 \pm 95.23 \mathrm{MPa})(\mathrm{p} \leq 0.001)$. Storage in distilled water did not significantly affect the E-modulus of Paladon $65(2771.80 \pm 79.23 \mathrm{MPa})(\mathrm{p}>0.05)$, Futura Gen $(2835.00 \pm 113.60 \mathrm{MPa})(\mathrm{p}>0.05)$ and FuturAcryl $2000(2766.60 \pm 91.22$ MPa) $(p>0.05)$ specimens (Figure 3 , Table 1 ). The E-modulus of the disinfected test specimens did not alter significantly compared to the reference value of distilled water $(\mathrm{p}>0.05)$ (Figure 3, Table 1).

\subsection{Flexural Strength}

Results are given as means \pm standard deviation (Figure 4, Table 2). For comparable evaluations of the flexural strength, the proof stress limit $\left(\varepsilon_{\mathrm{x}}\right)$ was set at $1 \%$. Measurements of the flexural strength were taken using all of the different denture materials prior to immersion in the tested disinfecting agents and the distilled water control group. Data of flexural strength testing ranged from 29.74 $\pm 1.84 \mathrm{~N} / \mathrm{mm}^{2}$ (Paladon 65) to $32.38 \pm 0.80 \mathrm{~N} / \mathrm{mm}^{2}$ (PalaXpress) of the dry stored test specimens.

The flexural strength of the PalaXpress test specimen decreased after storage in distilled water to $29.68 \pm 0.79 \mathrm{~N} / \mathrm{mm}^{2}$ ( $\mathrm{p} \leq 0.001$ ), but not the others decreased significantly (Paladon $6528.42 \pm 0.84 \mathrm{~N} / \mathrm{mm}^{2}$ ( $\mathrm{p}>0.05$ ), Futura Gen $29.28 \pm 0.93 \mathrm{~N} / \mathrm{mm}^{2}$ ( $\left.\mathrm{p}>0.05\right)$, FuturAcryl $200028.50 \pm 0.60 \mathrm{~N} / \mathrm{mm}^{2}(\mathrm{p}>0.05)$ ). The disinfection agents had no significant influence on the flexural strength (Figure 4, Table 2).

\subsection{Color Stability}

Results are given as means \pm standard deviation (Figure 5, Table 3). Color 
Table 1. Means and standard deviation of the E-Modulus after storage in different disinfection agents.

\begin{tabular}{|c|c|c|c|}
\hline Denture base resin & Disinfection agent & $\begin{array}{l}\text { Means } \\
{[\mathrm{MPa}]}\end{array}$ & $\begin{array}{c}\text { Standard deviation } \\
{[\mathrm{MPa}]}\end{array}$ \\
\hline \multirow[t]{5}{*}{ PalaXpress } & Dry storage & $3149.2^{*}$ & 77.61 \\
\hline & Distilled water & $2851^{*}$ & 95.23 \\
\hline & Impresept & 3004.2 & 26.4 \\
\hline & Stammopur & 2957 & 93.57 \\
\hline & D 050 Instru-Gen & 2976.6 & 79.29 \\
\hline \multirow[t]{5}{*}{ Paladon 65} & Dry storage & 2897 & 17.17 \\
\hline & Distilled water & 2771.8 & 9.23 \\
\hline & Impresept & 2647.6 & 157.1 \\
\hline & Stammopur & 2811.4 & 199.65 \\
\hline & D 050 Instru-Gen & 2867.6 & 213.87 \\
\hline \multirow[t]{5}{*}{ Futura Gen } & Dry storage & 2867.8 & 122.38 \\
\hline & Distilled water & 2835.0 & 113.6 \\
\hline & Impresept & 28538 & 195.8 \\
\hline & Stammopur & 2851.6 & 98.22 \\
\hline & D 050 Instru-Gen & 2773.8 & 154.77 \\
\hline \multirow[t]{5}{*}{ FuturAcryl 2000} & Dry storage & 3020 & 223.3 \\
\hline & Distilled water & 2766.6 & 91.22 \\
\hline & Impresept & 2780 & 75.77 \\
\hline & Stammopur & 2688.8 & 230.78 \\
\hline & D 050 Instru-Gen & 2881.8 & 58.3 \\
\hline
\end{tabular}

${ }^{*} \mathrm{p}<0.001$.

Table 2. Means and standard deviation of the flexural strength after storage in different disinfection agents.

\begin{tabular}{cccc}
\hline Denture base resin & Disinfection agent & $\begin{array}{c}\text { Means } \\
{\left[\mathrm{N} / \mathrm{mm}^{2}\right]}\end{array}$ & $\begin{array}{c}\text { Standard deviation } \\
{\left[\mathrm{N} / \mathrm{mm}^{2}\right]}\end{array}$ \\
\hline PalaXpress & Dry storage & $32.38^{*}$ & 0.80 \\
& Distilled water & $29.68^{*}$ & 0.79 \\
& Impresept & 30.88 & 0.25 \\
& Stammopur & 30.64 & 1.01 \\
& D 050 Instru-Gen & 30.68 & 0.65 \\
Paladon 65 & Dry storage & 29.74 & 1.84 \\
& Distilled water & 28.42 & 0.84 \\
& Impresept & 27.28 & 1.30 \\
& Stammopur & 28.68 & 1.81 \\
& D 050 Instru-Gen & 29.16 & 2.06 \\
Futura Gen & Dry storage & 29.92 & 1.17 \\
& Distilled water & 29.28 & 0.93 \\
& Impresept & 29.58 & 1.53 \\
& Stammopur & 29.60 & 1.08 \\
& D 050 Instru-Gen & 28.82 & 1.59 \\
& Dry storage & 30.90 & 2.08 \\
\hline
\end{tabular}




\section{Continued}

\begin{tabular}{ccc}
\hline Distilled water & 28.50 & 0.60 \\
Impresept & 28.82 & 0.52 \\
Stammopur & 27.48 & 2.22 \\
D 050 Instru-Gen & 29.32 & 0.49 \\
\hline
\end{tabular}

$\mathrm{p}<0.001$.

Table 3. Means and standard deviation of the color change after storage in different disinfection agents.

\begin{tabular}{cccc}
\hline Denture base resin & Disinfection agent & Means & Standard deviation \\
\hline PalaXpress & Distilled water & 1 & 1.14 \\
& Impresept & 0.91 & 1.13 \\
& Stammopur & 0.78 & 0.48 \\
& D 050 Instru-Gen & 0.99 & 1.06 \\
Paladon 65 & Distilled water & $0.92^{*}$ & 0.67 \\
& Impresept & $1.78^{*}$ & 1.51 \\
& Stammopur & 0.59 & 0.26 \\
& D 050 Instru-Gen & 0.59 & 0.34 \\
& Distilled water & 0.66 & 0.32 \\
& Impresept & 0.62 & 0.52 \\
& Stammopur & 0.78 & 1.03 \\
& D 050 Instru-Gen & 0.7 & 0.57 \\
FuturAcryl 2000 & Distilled water & $0.7^{*}$ & 0.47 \\
& Impresept & 0.71 & 0.53 \\
& Stammopur & $1.25^{*}$ & 1.18 \\
& D 050 Instru-Gen & $2.5^{*}$ & 1.8
\end{tabular}

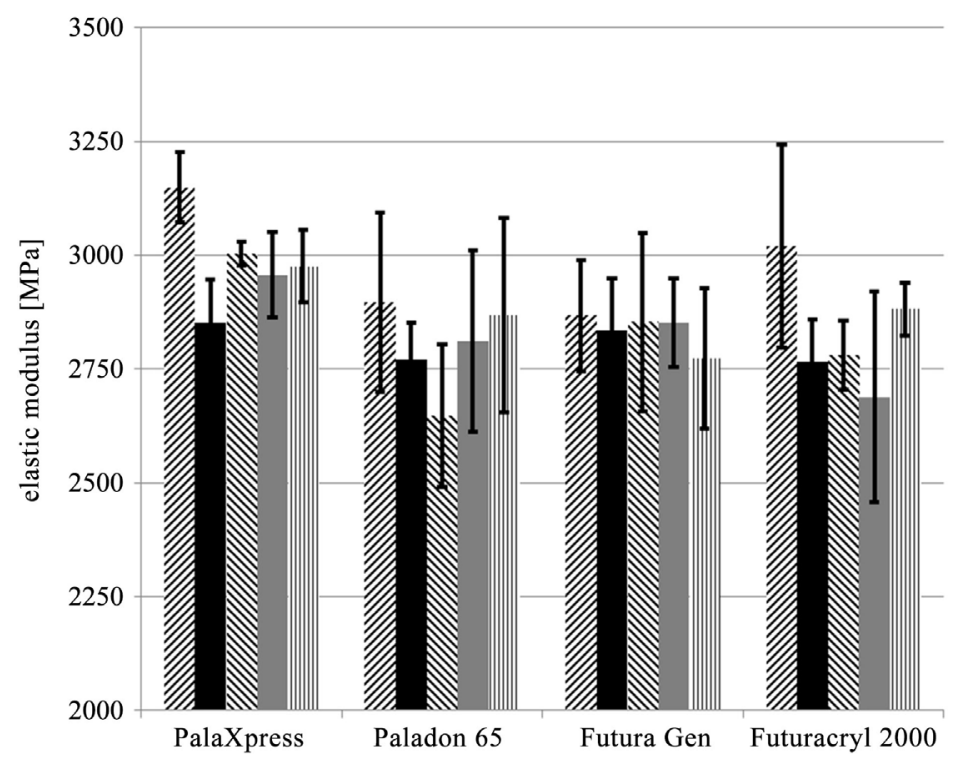

Figure 3. Modification of the elastic modulus of the denture base resins according to the disinfection agents $(/ /$ dry storage, $\mathbf{\square}$ distilled water, N Impresept, - Stammopur DR, |||| D 050 Instru-Gen). Results are given as means \pm standard deviation. 


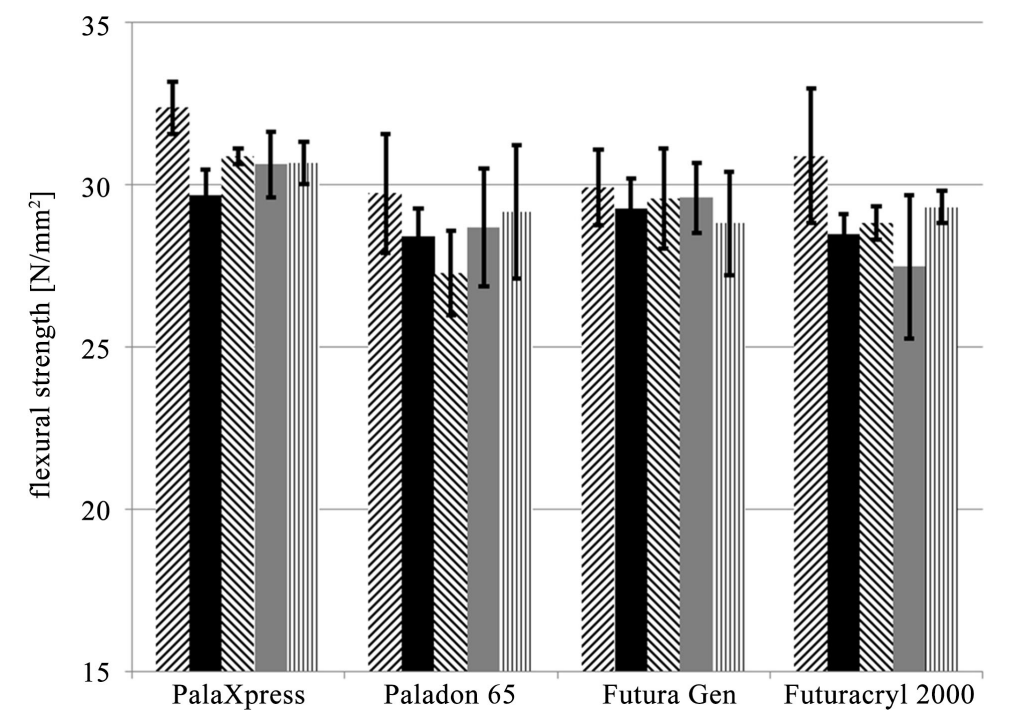

Figure 4. Modification of the flexural strength of the denture base resins according to the disinfection agents $(\mathbb{Z}$ dry storage, $\mathbf{a}$ distilled water, $\mathbb{N}$ Impresept, - Stammopur DR, IIII D 050 Instru-Gen). The proof stress limit $\left(\varepsilon_{\mathrm{x}}\right)$ was set at $1 \%$. Results are given as means \pm standard deviation.

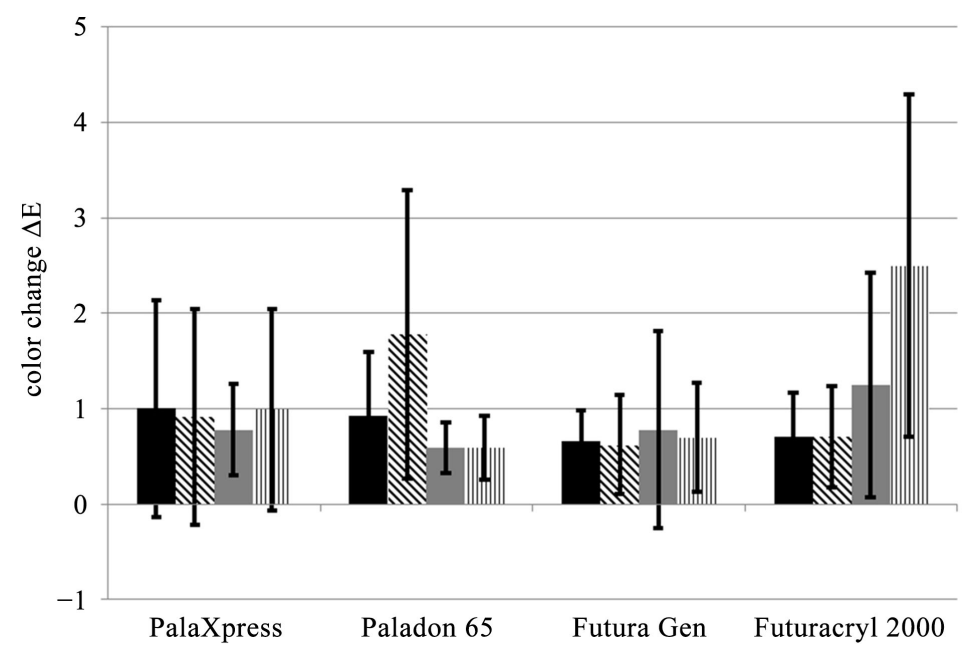

Figure 5. Modification of the color change of the denture base resins according to the disinfection agents $(\square \Delta$ distilled water, $\mathbb{N} \Delta$ Impresept, - $\Delta$ Stammopur DR, III $\Delta$ D 050 Instru-Gen). Results are given as means \pm standard deviation.

change of denture base materials can be noticed subjectively by human eyes starting from a value of $\Delta \mathrm{E} \geq 2$.

Water immersion of PMMA-based resins in distilled water caused a color change of the test specimens. $\Delta \mathrm{E}$-values ranged from $\Delta \mathrm{E} 0.66 \pm 0.32$ (Futura Gen) in the minimum to $\Delta \mathrm{E} 1.00 \pm 1.14$ (PalaXpress) in the maximum (Figure 5 , Table 3).

The cold-curing resins PalaXpress and Futura Gen did not significantly alter color of the material after disinfection. The disinfection with Impresept caused a significant color change of Paladon $65 \Delta \mathrm{E} 1.78 \pm 1.51$ ( $\mathrm{p} \leq 0.001)$. Color change 
of Futura Acryl 2000 after disinfection with Stammopur DR $\Delta$ E1.25 \pm 1.18 and D 050 Instru-Gen $\Delta$ E $2.50 \pm 1.80$ was significant $(\mathrm{p} \leq 0.001)$ (Figure 5, Table 3 ).

\section{Discussion}

In this present in vitro-study the influence of common dental disinfection agents on elastic modulus, flexural strength and color stability of PMMA-based resins was established. Two cold-curing (PalaXpress and Futura Gen) and two heat-curing (Paladon 65 and FuturAcryl 2000) PMMA-based resins were used [13]. The test specimens were covered by three disinfecting agents containing different primary active ingredients. Impresept and Stammopur DR were included in the aldehydes group of disinfecting agents. The disinfecting mode of action of D 050 InstruGen were oxidizing connections. Reference test series were performed using distilled water to compare the influence of water immersion compared to the possible effect of the disinfecting agents.

The investigated PMMA-based resins performed no significant effect according to the E-modulus after disinfection compared to the distilled water reference test group (Figure 3). PalaXpress test specimens showed after disinfection with Stammopur DR $(2957.00 \pm 93.57 \mathrm{MPa})$ minor changes and after disinfection with Impresept $(3004.20 \pm 26.40 \mathrm{MPa})$ the largest deviation according to the reference value of distilled water $(2851.00 \pm 95.23 \mathrm{MPa})$ (Figure 3). The results of Paladon 65 after disinfection with Stammopur DR $(2811.40 \pm 199.65 \mathrm{MPa})$ were close to the reference value of distilled water. The E-modulus values of $\mathrm{Pa}$ ladon 65 after disinfection with Impresept $(2647.60 \pm 157.10 \mathrm{MPa})$ showed the most deviation to the reference values of distilled water (Figure 3). However, the test results of Futura Gen after disinfection with Impresept $(2853.80 \pm 195.80$ $\mathrm{MPa}$ ) changed very little compared to the distilled water data, the largest deviation performed D 050 Instru-Gen (2773.80 $\pm 154.77 \mathrm{MPa})$. Disinfection of FuturAcryl 2000 with Impresept $(2780.00 \pm 75.77 \mathrm{MPa})$ performed the smallest variation to the reference values. After disinfection with D 050 Instru-Gen $(2881.80 \pm 58.30 \mathrm{MPa})$ the largest deviation was detectable (Figure 3). Taken together, disinfection of the investigated PMMA-based resins had no significant influence on elastic modulus (Figure 3) [13]. The minimum requirements for the E-modulus of the investigated PMMA-based resins of $\geq 2000 \mathrm{MPa}$ (ISO 1576) were fulfilled. However, the high level of variance of the standard deviation values regarding to volume determined elasticity indicates a relatively inferior status of homogenization of the test specimens (Figure 3) [14].

Compared to the distilled water reference test group, the investigated PMMA-based resins showed no significant effect to the flexural strength after disinfection (Figure 4). PalaXpress performed after storage in Stammopur DR $\left(30.64 \pm 1.01 \mathrm{~N} / \mathrm{mm}^{2}\right)$ minor changes and after disinfection with Impresept $\left(30.88 \pm 0.25 \mathrm{~N} / \mathrm{mm}^{2}\right)$ the largest deviation according to reference value of distilled water. Paldon 65 showed results after disinfection with Stammopur DR $\left(28.86 \pm 1.81 \mathrm{~N} / \mathrm{mm}^{2}\right)$, that were close to the reference value of distilled water. Flexural strength of Paladon 65 differed most after storage in Impresept (27.28 \pm 
$1.30 \mathrm{~N} / \mathrm{mm}^{2}$ ) compared to the reference values of distilled water. Test results of Futura Gen changed very little after disinfection with Impresept $(29.58 \pm 1.53$ $\mathrm{N} / \mathrm{mm}^{2}$ ) in terms of the data of the distilled water control group. The largest deviation was detected after disinfection with D 050 Instru-Gen $(28.82 \pm 1.59$ $\mathrm{N} / \mathrm{mm}^{2}$ ). The smallest variation to the reference values performed FuturAcryl 2000 after disinfection with Impresept $\left(28.82 \pm 0.52 \mathrm{~N} / \mathrm{mm}^{2}\right)$. The largest variation was detectable after disinfection with D 050 Instru-Gen $(29.32 \pm 0.49$ $\mathrm{N} / \mathrm{mm}^{2}$ ) (Figure 4). However, the results of this investigation are hardly comparable to other findings in literature. Thus, the proof stress limit $\left(\varepsilon_{\mathrm{x}}\right)$ was set individually at $1 \%$.

Single used isinfection of PMMA-based denture base resins had no significant effect on elastic modulus and flexural strength (Figure 3, Figure 4) [15]. These findings are in contrast to the initial hypothesis. However, the elastic modulus and flexural strength of the PalaXpress-specimens decreased significantly after storage in distilled water compared to dry storage (Figure 3, Figure 4). The wet storage leads to a diffusion of water molecules into the material, which in turn leads to swelling and a plasticizing effect. That results in a decrease of the elastic modulus of these materials [16] [17] [18]. However, the disinfection of the tested PMMA-based denture base resins did not influence the investigated material properties relating to elastic modulus and flexural strength significantly (Figure 3, Figure 4) [15]. For general disinfecting instructions regarding to E-modulus and flexural strength, the three tested disinfecting agents can be applied to everyday use [19] [20].

The storage in distilled water lead to color change of the test specimens from $\Delta \mathrm{E} 0.66 \pm 0.32$ to $\Delta \mathrm{E} 1.00 \pm 1.14$ (Figure 5). The data analysis of the color measurement shows that the investigated disinfection agents did not produce any significant color change on PalaXpress and Futura Gen (Figure 5). On the other hand, the disinfection of Paladon 65 with Impresept $(\Delta \mathrm{E} 1.78 \pm 1.51)$ and FuturAcryl 2000 with Stammopur DR $(\Delta \mathrm{E} 1.25 \pm 1.18)$ caused significant color changes compared to the control group (Figure 5). The clinical relevance of these results may be marginal, due to the fact that the measured $\Delta \mathrm{E}$-values were in a range of 1 to 2 points. These $\Delta \mathrm{E}$-values are usually not perceived visually [21] [22]. Only $\Delta \mathrm{E}$-values higher than 2 are visually perceptible. So only the disinfection agent D 050 Instru-Gen had a color changing effect on FuturAcryl $2000(\Delta \mathrm{E} 2.50 \pm 1.80)$ (Figure 5). The data shows that the disinfection process was causal for this specific color change on FuturAcryl 2000. The use of Impresept for disinfection of PalaXpress $(\Delta \mathrm{E} 0.91 \pm 1.13)$ and Paladon $65(\Delta \mathrm{E} 1.78 \pm$ 1.51) caused visually undetectable color alterations (Figure 5) [22].

In summary the three investigated disinfection agents, two of them containing glutaraldehyde and one of them contain oxidizing connections, did not produce any significant changes in the tested material parameters of E-modulus and flexural strength of the PMMA-based resins [12] [15]. Processing of acrylic dentures may subject them to numerous possibilities for defects, which result in porosities, shape deviations, and failures of surface structures. Void producing de- 
fects impair the structure and downgrade the physical and biological quality of denture base resins. Additionally, these defects have a negative influence on the hygienic characteristics and they compromise the esthetics of the PMMA-based resins [17] [23]. Therefore, high pressure is typically used to reduce the described defects during the polymerization process [17] [23].

In principle it is difficult to estimate how often a denture is disinfected during its clinical service time. Dental prostheses have to be disinfected for the first time before delivery [7] [24]. Thus, in this study the influence of single use disinfection was tested. In general, disinfecting agents should carry a wide application range. The disinfecting agent Impresept is recommended by the manufacturer for the disinfection of dental impression materials and is certified as surface disinfectant [25]. The results of this study imply that disinfection with Impresept does not impair the investigated material properties of PMMA-based resins. The universal applicability of disinfecting agents for both dental impressions and denture prosthesis is time saving and cost effective. Denture base resins are one of the most commonly used materials in the dental practice. The utilization of removable dentures will increase in the future with the expected change in demographics [5]. Thus, it is essential to understand the compatibility of utilized materials and to establish safe as well as standardized hygiene measures in the dental practice [7] [26]. The objective of all infection control procedures is to prevent transmission of infections between treated patients, dental staff and dental technicians.

A limitation of this study is the investigation of the single use disinfection. This describes the newly manufactured dental prostheses. For simulating the daily clinical practice, further studies should investigate the influence of repeated applications of disinfection agents on PMMA-based dentures. Repairs of dental prostheses could be prepared for simulating the averaged wearing period of dental prostheses. In addition, different material properties of PMMA-based resins have to be examined.

\section{Conclusion}

In this study, it was demonstrated that the investigated disinfecting agents did not influence elastic modulus and flexural strength of the tested denture base resins negatively. Further studies should verify the impact of long term disinfection intervals on the material properties of acrylic denture base resins.

\section{Acknowledgements}

The authors thank Dr. Seth Bozarth, DMD, Tufts University, Boston and Dr. Jamie N. Amir, DDS, Ocala, Florida, USA for their technical support and for their comments of the manuscript.

\section{Conflict of Interest}

The authors declare that they have no conflict of interest. 


\section{References}

[1] Bolyard, E.A., Tablan, O.C., Williams, W.W., Pearson, M.L., Shapiro, C.N. and Deitchman, S.D., Hospital Infection Control Practices Advisory Committee (1998) Guideline for Infection Control in Health Care Personnel, 1998. American Journal of Infection Control, 26, 289-354. https://doi.org/10.1016/S0196-6553(98)80015-1

[2] Jakubovics, N., Greenwood, M. and Meechan, J.G. (2014) General Medicine and Surgery for Dental Practioners: Part 4. Infections and Infection Control. British Dental Journal, 217, 73-77. https://doi.org/10.1038/sj.bdj.2014.593

[3] Chiarello, L.A. and Bartley, J. (2001) Prevention of Blood Exposure in Healthcare Personnel. Seminars in Infection Control, 1, 30-43.

[4] Smith, A.J., Wilson, S.L., Read, S., Welsh, J., Gammie, E., Szuster, J., Davidson, J. and Binnie, V. (2014) Patients' Perception of Infection Prevention in Dental Practice. American Journal of Infection Control, 42, 337-339.

https://doi.org/10.1016/j.ajic.2013.09.017

[5] Montero, J., Castillo-Oyagüe, R., Lynch, C.D., Albaladejo, A. and Castaño, A. (2013) Self-Perceived Changes in Oral Health-Related Quality of Life after Receiving Different Types of Conventional Prosthetic Treatments: A Cohort Follow-Up Study. Journal of Dentistry, 41, 493-503. https://doi.org/10.1016/j.jdent.2013.01.006

[6] Powell, G.L., Runnells, R.D., Saxon, B.A. and Whisenant, B.K. (1990) The Presence and Identification of Organisms Transmitted to Dental Laboratories. Journal of Prosthetic Dentistry, 64, 235-237. https://doi.org/10.1016/0022-3913(90)90185-F

[7] Centers for Disease Control (CDC) and Prevention (2003) Guidelines for Infection Control in Dental Health-Care Settings-2003. $M M W R$, 52,33-34.

[8] Brace, M.L. and Plummer, K.D. (1993) Practical Denture Disinfection. Journal of Prosthetic Dentistry, 70, 538-540. https://doi.org/10.1016/0022-3913(93)90268-S

[9] Shen, C., Javid, N.S. and Colaizzi, F.A. (1989) The Effect of Glutaraldehyde Base Disinfection on Denture Base Resins. Journal of Prosthetic Dentistry, 61, 583-589. https://doi.org/10.1016/0022-3913(89)90281-3

[10] Foliente, R.L.K.B., Aprecio, R.M., Bains, H.J., Kettering, J.D. and Chen, Y.K. (2001) Efficacy of High-Level Disinfectants for Reprocessing Gastrointestinal Endoscopes in Simulated-Use Testing. Gastrointestinal Endoscopy, 53, 456-462. https://doi.org/10.1067/mge.2001.113380

[11] Kovacs, B.J., Chen, Y.K., Kettering, J.D., Aprecio, R.M. and Roy, I. (1999) High-Level Disinfection of Gastrointestinal Endoscopes: Are Current Guidelines Adequate? The American Journal of Gastroenterology, 94, 1546-1550. https://doi.org/10.1111/j.1572-0241.1999.01142.x

[12] Pavarina, A.C., Machado, A.L., Giampaolo, E.T. and Vergani, C.E. (2003) Effects of Chemical Disinfectants on the Transverse Strength of Denture Base Acrylic Resins. Journal of Oral Rehabilitation, 30, 1085-1089. https://doi.org/10.1046/j.1365-2842.2003.01150.x

[13] Pfeiffer, P., Rolleke, C. and Sherif, L. (2005) Flexural Strength and Moduli of Hypoallergenic Denture Base Materials. Journal of Prosthetic Dentistry, 93, 372-377. https://doi.org/10.1016/j.prosdent.2005.01.011

[14] Phoenix, R.D. (1996) Denture Base Materials. Dental Clinics of North America, 40, 113-120.

[15] Asad, T., Watkinson, A.C. and Huggett, R. (1992) The Effect of Disinfection Procedures on Flexural Properties of Denture Base Acrylic Resins. Journal of Prosthetic Dentistry, 68, 191-195. https://doi.org/10.1016/0022-3913(92)90303-R 
[16] Joshi, N.P. and Sanghvi, S.J. (1994) Water Sorption by Maxillary Acrylic Resin Denture Base and Consequent Changes in Vertical Dimension. Journal of Pierre Fauchard Academy, 8, 97-106.

[17] Wong, D.M., Cheng, L.Y., Chow, T.W. and Clark, R.K. (1999) Effect of Processing Method on the Dimensional Accuracy and Water Sorption of Acrylic Resin Dentures. Journal of Prosthetic Dentistry, 81, 300-304. https://doi.org/10.1016/S0022-3913(99)70273-8

[18] Duymus, Z.Y. and Yanikoglu, N.D. (2004) Influence of a Thickness and Processing Method on the Linear Dimensional Change and Water Sorption of Denture Base Resins. Dental Materials Journal, 23, 8-13. https://doi.org/10.4012/dmj.23.8

[19] Blair, F.M. and Wassel, R.W. (1996) A Survey of the Methods of Disinfection of Dental Impressions used in Dental Hospitals in the United Kingdom. British Dental Journal, 180, 369-375. https://doi.org/10.1038/sj.bdj.4809092

[20] da Silva, F.C., Kimpara, E.T., Mancini, M.N., Balducci, I., Jorge, A.O. and Koga-Ito, C.Y. (2008) Effectiveness of Six Different Disinfectants on Removing Five Microbial Species and Effects on the Topographic Characteristics of Acrylic Resin. Journal of Prosthodontics, 17, 627-633. https://doi.org/10.1111/j.1532-849X.2008.00358.x

[21] Polyzois, G.L., Yannikakis, S.A., Zissis, A.J. and Demetriou, P.P. (1997) Color Changes of Denture Base Materials after Disinfection and Sterilization Immersion. The International Journal of Prosthodontics, 10, 83-89.

[22] Ma, T., Johnson, G.H. and Gordon, G.E. (1997) Effects of Chemical Disinfectants on the Surface Characteristics and Color of Denture Resins. The Journal of Prosthetic Dentistry, 77, 197-204. https://doi.org/10.1016/S0022-3913(97)70235-X

[23] Zissis, A.J., Polyzois, G.L., Yannikakis, S.A. and Harrison, A. (2000) Roughness of Denture Materials: A Comparative Study. The International Journal of Prosthodontics, 13, 136-140.

[24] Bensel, T., Pollak, R., Stimmelmayr, M. and Hey, J. (2013) Disinfection Effect of Dental Impression Tray Adhesives. Clinical Oral Investigations, 17, 497-502. https://doi.org/10.1007/s00784-012-0735-Z

[25] Bock, J.J., Fuhrmann, R.A. and Setz, J. (2008) The Influence of Different Disinfectants on Primary Impression Materials. Quintessence International, 39, 93-98.

[26] Jarwis, W.R. (2007) The United States Approaches to Strategies in the Battle against Healthcare-Associated Infections: Transitioning from Benchmarking to Zero Tolerance and Clinician Accountability. Journal of Hospital Infection, 65, 3-9. https://doi.org/10.1016/S0195-6701(07)60005-X 